\title{
JUECES Y DEMOCRACIA. \\ EL PAPEL DE LA MAGISTRATURA Y DEMOCRACIA PENAL; EL USO JUDICIAL DEL DERECHO PENAL DE LOS PRINCIPIOS
}

\author{
Massimo Donini ${ }^{1}$ \\ Università di Modena e Reggio Emilia
}

\begin{abstract}
1. El fenómeno de la expansión mundial del poder judicial 2. Espacios para una legítima política interpretativa del juez a la luz de los principios constitucionales 3. La experiencia italiana de reinterpretación del Código penal de modo conforme a la Constitución 4. El principio de subsidiariedad entre competencia del poder politico y el papel del juez. 5. Derecho penal y democracia: antinomias y convergencias de una relación difícil
\end{abstract}

\section{El fenómeno de la expansión mundial del poder judicial.}

El poder judicial ha conocido, en los últimos lustros, aquello que ha sido adecuadamente definido como una expansión global.

Se trata de un fenómeno que, por definición, expresa una crisis de la legalidad como modelo "fuerte" de solución preconstituida de los conflictos.

En el origen de tal fenómeno existen tres causas o al menos tres factores desencadenantes.

El primero es la pérdida de poder soberano de los Estados y de la misma "ley", en un contexto de globalización, por un lado, y de privatización y particularización, por el otro, de las decisiones político-económicas.

El segundo es el desarrollo del derecho de los principios de la Carta constitucional y de los actos supranacionales, que se superponen y se sustituyen al gobierno de las "reglas" parlamentarias.

El tercero está dado por la conciencia colectiva de la importancia cada vez mayor del derecho aplicado, de la law in action respecto del derecho escrito.

\footnotetext{
${ }^{1}$ Traducción de María Inés Horvitz Lennon (Universidad de Chile) y Raúl Carnevali Rodríguez (Universidad Alberto Hurtado)

2 TATE/VALLINDER (Eds.), The Global Expansion of Judicial Power, 1 ss., 27 ss. y passim; L.M. FRIEDMAN, Total Justice, passim; HOLLAND, Judicial Activism in Comparative Perspective, passim. Las publicaciones acerca de las relaciones entre los jueces y la democracia, o entre los jueces y política, en los últimos años, han aumentado significativamente. Recuerdo sólo (además de las numerosas contribuciones sobre corrupción institucional y Tangentopoli), entre la literatura aparecida en Italia, PIZZORNO, Il potere dei giudici, passim; GUARNIERI/PEDERZOLI, La democrazৃia giudiẓiaria, (con amplia bibliografía); ID., La magistratura nelle democrazie contemporanee, passim; GARAPON, Le gardien des promesses, tr. it., passim; GARAPON/SALAS, La République pénalisée (1996), tr. it., passim; COLAJANNI, Mani pulite? Giustizia e politica in Italia, passim; SCODITTI, Il contropotere giudiziario, passim; RIGHETTINI, La politicizzarione di un potere neutrale, 227 ss.; AA.VV., Giudici e democrazi, passim; P. PASQUINO, Uno e trino. Indipendenza della magistratura e separazione dei poteri, passim; SOULEZ LARIVIERE, Du cirque médiatico-judiciaire, tr. it., passim.
} 
Con relación a la pérdida de soberanía de los Estados se aprecia que la ley está actualmente más condicionada, en su contenido, a decisiones adoptadas extramuros del Parlamento que la aprueba: sean esas fuentes transnacionales (por ejemplo, el derecho comunitario para Europa), o bien se trate de acuerdos internacionales, decisiones políticoeconómicas externas, las que producen fuertes consecuencias en la legislación de los Estados nacionales, etc., o se trate, incluso, de decisiones de grupos de presión, lobbies, empresas, que "contratan" fuera del Parlamento el "estatuto penal" que los proteja; o se trate ya de fuentes jurídicas subordinadas a la ley, pero muy importantes para dotarlas de contenido. Es verdad, entonces, y con relación al derecho penal en particular, que sobre todo ello domina el ordenamiento jurídico general: si se quiere conocer la licitud de una conducta, con la excepción de pocos delitos naturales en que resulta claro para todos que se trata de actos delictivos, es más prudente consultar primero el ordenamiento jurídico extrapenal: quien parte por el orden jurídico penal corre el riesgo de desviarse. Empero, en el ordenamiento extrapenal muchas fuentes operan por fuera de una verdadera subordinación respecto a principios y reglas penales coexistentes: por ello, tales diversas "fuentes" deberían estar coordinadas, antes que colocadas en una relación de mera ejecución respecto a las otras. intérprete.

Esta complejidad disminuye el papel ordenador del Estado y aumenta aquel del

Hoy en día se habla, por lo demás, de un sistema jurídico que no es más "piramidal"jerárquico (donde la fuente inferior, por ejemplo la ley respecto de la Constitución, es una relación de "ejecución" respecto a la fuente superior), sino "una red", porque las fuentes interaccionan de modo no jerárquico y deben estar "coordinadas" entre ellas, antes que situarse en relaciones rígidas de subordinación o de supraordenación.

El entrelazado reticular de las fuentes tiene evidentemente que ver con la debilidad jerárquica de la ley, e incluso con el incremento del poder judicial, porque esto hace a una pérdida del poder soberano de los Estados, una pérdida de soberanía en la que muchos reconocen aspectos esenciales de la globalización ${ }^{3}$ : ello proviene de la circunstancia de que muchas decisiones de política económica se adoptan, hoy, en el nivel supraestatal, por poderes económicos transversales respecto de los Estados, sea que ellos resulten representados en organismos internacionales de control de la economía, por ejemplo, el Banco Mundial, el Fondo Monetario Internacional (FMI), la Organización Mundial del Comercio (WTO); o sea, que operen por fuera de estos últimos. Hay, por tanto, una ausencia de dirección jurídica $y$, en consecuencia, una desautorización a los Estados nacionales, en la que se afianza una governance económica: a la governance económica global no corresponde, sin embargo, un gobierno global sino una "governance", esto es, un complejo de actores constituido por Estados, mercados, movimiento y comunidad ${ }^{4}$.

El segundo factor del aumento del poder judicial está constituido por el derecho (penal) de los principios.

\footnotetext{
${ }^{3}$ Por ejemplo, ROSENAU, Sovereignty in a Turbulent World, 191 ss.; BECK, Was ist Globalisierung?, 24 ss.; HELD, Law of States, Law of People, 1 ss. Para una reflexión sobre la soberanía en este nuevo orden, v. también, HARDT/NEGRI, Empire, tr. it., passim.

${ }^{4}$ Sobre las perspectivas de una governance mundial democrática v. MARTINELLI, La democrazia globale, $115 \mathrm{ss.}$
} 
Cualquiera sea el contenido que el Parlamento pretenda dar a la ley, su funcionamiento real, su aplicación, será siempre más limitado que los principios superiores que fijan barreras insuperables a las mayorías parlamentarias, y son capaces de vaciar o modificar profundamente el alcance de una ley.

El único poder que realmente puede controlar las leyes a la luz de los principios es el poder judicial.

La magistratura, en efecto, además de controlar, de modo centralizado o difuso, la legitimidad de la ley, lleva a cabo una relación directa entre el poder público y cada uno de los ciudadanos: esto es algo que la ciencia jurídica no ha hecho nunca y que la política oficial ha dejado de hacer hace tiempo. La magistratura "compensa el 'déficit democrático' de la decisión política actualmente dedicada a la pura gestión y a dar a la sociedad aquel referente simbólico siempre menos identificable en el parlamento"5; ella se torna intérprete de los derechos de todos, y a veces de las minorías, frecuentemente contra las razones particulares o prevaricadoras de la política oficial, y lo hace "desde abajo", esto es, partiendo de los casos, de la pretensión de los interesados.

Otra razón central de tal incremento del poder judicial que, lejos de constituir un fenómeno italiano o europeo, "es común a todas las democracias liberales maduras”, está representada por las consecuencias que el pluralismo (ideológico, hermenéutico, de las fuentes, de los ordenamientos), en conjunto con la conflictividad de los intereses públicos y privados, produce sobre la gestión de la legalidad. Incluso, las leyes más antiguas se aplican en el contexto de "ponderación entre principios" que reorganizan su significado. Y las nuevas leyes siguen pronto la misma suerte.

Es la misma ley —en cuanto forma máxima de instrumento autoritativo constituido por reglas determinadas abstractamente (no por principios y valores más indeterminados)_ la que se manifiesta crecientemente incapaz de soluciones generalizadoras definitivas, según el paradigma de decisión parlamentaria, y que por eso se halla necesitada de niveles de decisión mucho más equilibradas, que debe delegar al poder judicial no sólo con relación al caso concreto sino también respecto de valores más generales. La ley, entonces, se "diferencia" también in action. Y este es el tiempo de un derecho penal diferenciado.

El tercer factor expresa la conciencia del gran 'peso' de la interpretación respecto a la letra de la ley, y es un resultado internacional de la cultura hermenéutica: ley y derecho son realidades distintas. La conciencia de este dato estaba ausente del proyecto de la codificación entre la segunda mitad del s. XIX y la primera mitad del s. XX y, actualmente, la consecuencia que de ello se deriva es la crisis del modelo de código y de sistema "cerrado" típico del s. XIX y, al mismo tiempo, la crisis de la concepción ejecutivo-deductiva (o silogística) de la interpretación de los textos legales.

Nadie piensa que quien conoce la ley penal conoce el derecho penal: este último está constituido por el texto legal más su interpretación y aplicación al caso. Nadie, por

\footnotetext{
${ }^{5}$ Así, eficazmente, GARAPON, Le gardien, tr. it., 33

${ }^{6}$ PIZZORNO, Il potere dei gindici, 6. En perspectiva comparada, v. por todos, los análisis de HOLLAND, Judicial Activism, passim; TATE/VALLINDER (ed.), The Global Expansion, passim; GUARNIERI/PEDERZOLI, La democrazia giudiriaria, passim.
} 
tanto, se ilusiona más con la idea que basta conocer la ley penal oficial, aquella publicada en los Diarios Oficiales. Sólo los comentarios doctrinales y jurisprudenciales dicen la verdad, como escribió ESSER, hace ya cincuenta años.

Este fenómeno produce, a su turno, una evolución de las tareas del poder judicial: no más el ejecutor de la imposición autoritaria de los deberes del ciudadano en general, sino el intérprete de los derechos del ciudadano y de las minorías, a través de disposiciones de la administración pública o la mediación de intereses de grupos contrapuestos. El intérprete, entonces, regula situaciones particulares, adapta la ley a la pluralidad de hechos, antes que llevar la variedad de la ley a una unidad superior. El estudio de las sentencias, cada vez más analíticas y minuciosas "demuestra" a todos que el derecho in action no es la mera ejecución de la ley escrita y esto, en buena medida es, natural e inevitable.

\section{Espacios para una política interpretativa legítima del juez, a la luz de los principios constitucionales.}

La expansión del poder judicial ha generado la acusación de una 'politización'de la magistratura, la que rompería las estructuras de la democracia liberal y de la división de los poderes, en una actividad de sustitución judicial, de democracia judicial que habría tomado el puesto de la democracia parlamentaria.

Sobre todo en el derecho penal existe una fuerte resistencia a admitir un papel del juez que no sea tendencialmente ejecutivo: dejarle un espacio "directamente" político en la interpretación genera el temor de que ello produzca necesariamente una extensión de la punibilidad, y por tanto una violación del principio de legalidad estricta y de prohibición de analogía (in malam partem).

En el derecho civil, del trabajo, de la familia, entre otros, se afirma que el discurso es distinto: aquí el juez, puede verdaderamente "alargar la esfera de los derechos" del ciudadano en general, extendiendo leyes indeterminadas, porque en el instante en el que, aplicando cualquier principio constitucional, él amplía la tutela de aquellos derechos, con ello da satisfacción a los intereses de una entera categoría de sujetos que resultan de esta manera protegidos, sin perjudicar la libertad y la dignidad de ninguno, incluso sólo por efecto del "estigma" que acompaña a la condena penal. Aquí no hay un imputado que proteger mediante la garantía formal de la ley, ni con la reserva absoluta de ley, ni con la prohibición de analogía in malam partem, ni con el vínculo constitucional de determinación, etc.

En el derecho penal, por el contrario, una operación similar no puede sino producir ilegalidad, porque extender la tutela de los derechos a las posibles víctimas significa inventar nuevos bienes jurídicos o nuevas tipologías de conductas punibles, con el fin de proteger a las personas ofendidas por estas "nuevas" agresiones: pero todo ello por fuera de la legalidad, de la reserva de ley, que "garantizan" los derechos del imputado, que son su "Magna Charta" como decía von Lišt.

En el derecho penal, por tanto, el único espacio para una intervención legítima del juez, para una "política interpretativa", estaría constituido por los derechos del imputado frente al Estado, no aquellos de la víctima o de la sociedad: el juez sólo podría "extender" la no punibilidad, efectuar interpretaciones restrictivas de las incriminaciones o extensivas de las causas de justificación, o bien rediseñar normas de la parte general en función limitadora de la responsabilidad, 
según una lógica de extrema ratio y subsidiariedad: disminuyendo así, el sufrimiento que la pena conlleva, jamás aumentándola.

Estas afirmaciones, que si bien son exactas en el plano teórico, tienen que ser corroboradas. Aunque ellas funcionan especialmente en los "casos fáciles" (que ciertamente constituyen la mayoría) y en el límite de un cuadro simple y ordinario de relaciones entre los poderes del Estado: un cuadro más cercano a un Estado regional y preindustrial, que no es el horizonte de una sociedad multicultural, transnacional y globalizada. "Los casos difíciles" y la actualidad de las fuentes complican, por tanto, la posibilidad de hacer operativo aquel paradigma tan "clásico" y racional.

Intentemos distinguir.

En el sistema del civil law, del derecho codificado, en el plano de la actividad interpretativa ordinaria, el juez penal (y el intérprete en general) debe enfrentarse con problemas de interpretación general de la ley (problemas generalizantes) y de aplicación de la ley a los casos (problemas individualizantes).

Entre ambas actividades se presentan casos fáciles y casos difíciles (hard cases). Los casos difíciles, sin embargo, son por fortuna menos numerosos que aquellos fáciles.

La verdadera actividad del juez en cada caso, lo que le es específicamente propio, consiste en aplicar reglas a casos singulares, no construir reglas para todos los casos; ellos no pueden eximirse de generar interpretaciones acabadas y cada interpretación de una norma particular produce repercusiones por el solo hecho de estar insertada en un complejo de reglas in fieri.

Cada regla del sistema cambia por el solo hecho de interaccionar con otras reglas que cambian. A veces, las normas resisten por muchos decenios sin experimentar variaciones en su aplicación. Es más, en muchos otros casos, después de pocos años de evolución rápida, todo un antiguo sistema de pensamiento y de tradición hermenéutica puede comenzar a experimentar transformaciones, primero, de apariencia marginal $y$, después, profundas. Las reglas vienen "desarmadas" y rearmadas, "deconstruidas".

Como las leyes son siempre en parte indeterminadas, el papel del intérprete, en estos espacios de indeterminación, es indispensable, dado que el legislador interviene raramente y con intermitencia. No hay analogía cuando lo que hay es indeterminación de la $\operatorname{ley}^{7}$.

Además, el juez. debe siempre advertir cuándo está extendiendo de modo innovador la punibilidad respecto a las interpretaciones pasadas, sin que opere una analogía probibida.

Y aquí debería introducirse una norma que prohíba la aplicación de estas innovaciones interpretativas (in malam partem) al caso concreto: para sí poderlas adoptar, pero sólo si confirman las decisiones de un órgano superior de control probibición de

\footnotetext{
${ }^{7}$ En el sentido de que cuando una ley es más indeterminada, tanto más admite, de hecho, que se lleven a cabo analogías "legales": sólo las reglas muy (o demasiado) taxativas evidencian lagunas, aquellas genéricas las esconden. El problema, por tanto, es a nivel de indeterminación, si son aún tolerables o más bien no. Un margen de indeterminación es propio de todas las normas.
} 
retroactividad de las interpretaciones desfavorables innovadoras). Ello, tal como prevé, a nivel europeo, el Proyecto de Código europeo en lo que se refiere a la protección de las finanzas de la CE, denominado Corpus Juris y el artículo 7 (sobre prohibición de retroactividad) de la Convención europea de los derechos del hombre, como se ha interpretado por la jurisprudencia de la Corte de Justicia.

Ahora bien, todos estos espacios de innovación hermenéutica se registran ya en la interpretación de la ley ordinaria y con prescindencia de la hermenéutica constitucional. Pero cuando interviene el derecho penal de los principios constitucionales, aumenta mucho la posibilidad de una "relectura" ex novo de un completo sistema penal.

Los principios y las reglas constitucionales obligan al juez a releer las leyes ordinarias según la norma fundamental. Las leyes ordinarias que no estén conforme con la Constitución son leyes inválidas y deben ser, o bien reinterpretadas de modo constitucional, o bien declaradas ilegítimas por el órgano competente si es puesta en su conocimiento la cuestión: si no son recurridas de legitimidad constitucional una norma ilegítima puede continuar existiendo por tiempo ilimitado.

\section{La experiencia italiana de re-interpretación del Código penal de modo conforme a la Constitución.}

La experiencia italiana, en este punto, es rica en ejemplos y muy ilustrativa.

Desde que la Constitución de 1947 entró en vigor, existe un Código Penal (de 1930) que nunca ha sido integralmente sustituido, esto es, de una sola vez, sino sólo "a pedazos", con reformas parciales, especialmente en el ámbito de la parte especial y del sistema sancionatorio. En los últimos 30 a 40 años se ha desarrollado un movimiento amplio de relectura del Código (y de las leyes especiales) según la Constitución. Eso se llama aproximación u orientación constitucional del derecho penal, que ya ha atravesado diversos "estadios".

De algunas normas de la Constitución se han derivado, por vía interpretativa, numerosos principios ${ }^{8}$ : legalidad, prohibición de retroactividad de las normas penales incriminadoras y también el principio de reserva (tendencialmente absoluta) de ley y el principio de taxatividad o suficiente determinación (art. 25 Constitución italiana); principio de responsabilidad por el propio hecho culpable o principio de culpabilidad (art. 27. 1 C.i.); principio de racionalidad y como corolario del principio de igualdad el de proporcionalidad

\footnotetext{
${ }^{8}$ Sobre los fundamentos constitucionales del Derecho penal en la literatura italiana, BRICOLA, voz Teoria generale del reato, en NSSDI, vol. XIX, Utet, Torino, 1973, passim. Para una revisión crítica más reciente, entre otros, MARINUCCI/DOLCINI, Costiturione e politica dei beni giuridici, en Riv. it. dir. proc. pen., 1994, 333 ss.; ROMANO M., Commentario sistematico del codice penale, vol. I33, Giuffrè, Milano, 2004, Pre-Art. 1/27 ss.; DONINI, Ragioni e limiti della fondazione del diritto penale sulla Carta costituzionale. L'insegnamento dell'esperienza italiana, en Foro it., 2001, V, 29, ahora en ID., Alla ricerca di un disegno. Scritti sulle riforme penali in Italia, Cedam, Padova, 2003, 37 ss.; ID., voz Teoria del reato, en Dig. Disc. Pen., vol. XIV, 1999, 226 ss., 265 ss.; PALAZZO, Introdurione ai principi, 142 ss.; MAZZACUVA, Diritto penale e Costitusione, en AA.VV., Introdurione al sistema penale, vol. I $^{2}$, a cargo de INSOLERA, MAZZACUVA, PAVARINI, ZANOTTI, Giappichelli, Torino, 2000, 79 ss.; FIANDACA, en FIANDACA/DI CHIARA, Una introdurione al sistema penale, Jovene, Napoli, 2003, 115 ss. (parágrafo: Nessun reato senæa offesa)
} 
(art. 3.1 C.i.); principio (expresamente previsto por la Constitución) de la finalidad reeducativa de la pena (art. 27.3 C.i.); principio de ofensividad, o de necesaria lesividad del delito (arg. ex art. 13, 25, 27 C.i.); a ellos se suman otros principios políticoconstitucionales, a veces definidos como criterios informadores o de orientación, y en otros casos como "características" del sistema penal (subsidiariedad, fragmentariedad, laicicidad, efectividad, materialidad, etc.).

Estos principios son de dos clases y tienen un diferente grado de "justiciabilidad": los demostrativos y aquellos de dirección política?

Los principios demostrativos (por ejemplo, legalidad, prohibición de retroactividad, reserva de ley, culpabilidad, etc.) deben aplicarse a todas las leyes, y si son violados por una ley, ella es inconstitucional. Existen, de hecho, criterios para valorar en modo suficientemente "técnico" el respeto de estos principios. Ellos son, por tanto, "justiciables", porque la Corte Constitucional puede aplicarlos y anular las leyes sin que pueda ser acusada de realizar elecciones ilegítimas de tipo político.

Los principios de dirección politica o "argumentativos", por el contrario (por ejemplo, de extrema ratio o subsidiariedad, defensa social, lesividad, etc.) no pueden ser utilizados aisladamente (sin el auxilio de otros principios o normas violados) para que la Corte Constitucional pueda declarar la inconstitucionalidad de una ley: ellos sirven para "argumentar", en conjunto con otros principios demostrativos, si una ley es legítima, porque no existen instrumentos técnicos adecuados para expresar la ley sobre la base de tales principios, sin que el juicio se vuelva demasiado "político" y, como tal, no consentido por la Corte Constitucional. Por ejemplo, hasta hoy resulta difícil que la Corte Constitucional declare la ilegitimidad de una norma penal en base a que el ilícito, por razones de extrema ratio, debió haber sido sólo de tipo administrativo: la elección del tipo de sanción, de hecho, se mantiene como una cuestión esencialmente política, y como tal, no justiciable por parte de la Corte.

Sin embargo, estos principios, sea demostrativos, sean de dirección politica (o argumentativos), son utilizables por los jueces ordinarios para interpretar las leyes, para re-interpretarlas según la Constitución, volviéndolos asi — tras la interpretación - constitucionalmente conformes. No sólo: la interpretación "adecuatoria", que conforma la ley a la Constitución, es imperativa para el juez, es un deber del juzgador, que tiene la obligación de aplicar sólo las leyes constitucionalmente conformes.

Ha ocurrido así que muchísimas normas del Código Rocco de 1930 han sido no sólo "releídas" a través de la Constitución, sino que de hecho "reescritas" por efecto de esta reinterpretación.

Esto es lo que más ha acontecido, en sentido liberal, restrictivo de la punibilidad, especialmente por parte de la doctrina. Por ejemplo, a través de la relectura de los bienes jurídicos del Código a la luz de la Constitución se han adaptado muchas interpretaciones más "laicas" (en materia de delitos contra la religión, las buenas costumbres, la moral), o bien más cercanas al requisito de lesividad (por ejemplo, en materia de delitos políticos, de atentado y también en muchísimos delitos comunes) o al de culpabilidad (eliminando

${ }_{9}$ Recogiendo las distinciones expuestas en DONINI, Teoria del reato. Una introdurione, Cedam, Padova, 1996, cap. I; ID., voz Teoria, cit. 
muchas hipótesis de responsabilidad objetiva), o el de taxatividad (eligiendo las interpretaciones que hacen más preciso y riguroso el contenido de una norma, en vez de aquellas que las hacen menos indeterminadas y manipulables), etc.

En la jurisprudencia, en cambio, el uso del derecho constitucional se ha efectuado en parte en la misma dirección liberal de la doctrina, cuyas propuestas se han recibido, pero en parte también para extender la punibilidad, vale decir, para reforzar la tutela de intereses o de personas descuidadas por la normativa vigente, por el retardo del Parlamento en satisfacer la exigencia de reforma.

Ha ocurrido así, que muchos delitos en materia de administración pública (por ejemplo, abuso de la función, corrupción, peculado, etc.) han sido interpretados de modo extensivo, en nombre de los valores constitucionales, para controlar la "legalidad" de la actividad de los poderes públicos por parte de la magistratura, o para extender el estatuto penal de los funcionarios públicos a otra categoría de sujetos (considerados) equiparables; lo mismo acontece en el control sobre la actividad edilicia (a través de concesiones "sustanciales" de los bienes protegidos por los delitos en materia de construcción abusiva), o sobre la empresarial (a través de interpretaciones extensivas de los delitos de falsedades en los balances, cuya transparencia es funcional a la protección del mercado, de la economía, etc. o bien extendiendo las posiciones de garante y, de esta manera, los delitos omisivos para la mejor tutela de los trabajadores), o sobre la actividad médico-quirúrgica y sobre la comisión de desastres ambientales o lesiones y homicidios derivados de la actividad industrial (a través de la extensión de la causación culposa y omisiva que deba imputarse, la protección de la salud y de la vida, resultados lesivos sólo quizás producidos, mediante el parámetro del aumento del riesgo), o sobre conductas de participación y asociación criminal (mediante la invención y la elaboración del denominado concurso externo en los delitos asociativos) y así, muchos otros.

Por ello, decimos que el uso del derecho penal de los principios, o bien de categorías ligadas a ellos, como la de bien jurídico "de relevancia constitucional", se presta no sólo para los fines del garantismo, sino también para operaciones indebidas, extensivas de la punibilidad. En tal caso, ello sucita muchas polémicas y también legítimas censuras, porque da lugar a interpretaciones denominadas "sustanciales" que fuerzan o rompen la división de los poderes, creando nuevas incriminaciones a través de la mera gestión "hermenéutica" de aquellas existentes. Estas operaciones son, por una parte, claramente ilegítimas; por otro lado, se encuadran, asimismo, en los denominados "casos difíciles", porque la relativa indeterminación de las normas, releídas a través de los principios, hace posible estas opciones hermenéuticas. Así, los casos difíciles dejan abierto el camino a una política judicial legitima aunque extensiva de la punibilidad.

Todo este discurso nos lleva a indagar las relaciones entre derecho penal y política, porque finalmente es la política, legítimamente construida en las instituciones, la que tiene la competencia para crear el derecho penal, pero sólo con respeto a los principios que se hallan supraordenados a ella y que no están en la libre gestión de las mayorías parlamentarias. 


\section{El principio de subsidiariedad entre competencia del poder político y función del juez.}

El principio más importante de la política criminal (y que en muchos ordenamientos tiene, aunque sea indirectamente, un fundamento constitucional) es aquel de extrema ratio o subsidiariedad, el cual significa que, primero, está la prevención, la política social, las sanciones extrapenales y sólo entonces se puede recurrir a la pena. La solución de los problemas sociales no puede servir de apoyo para utilizar el derecho penal como arma principal. Ya el hecho de colocar en ello muchas esperanzas es señal de un uso indebido de la pena $y$, por tanto, de la libertad de los ciudadanos. La pena se justifica cuando existe aquella prevención, aquella política social, aquel aparato extrapenal. Este juicio, sin embargo, se encuentra hoy a la libre gestión de los partidos políticos, del poder político, porque el jurista no posee todavía una verdadera ciencia de la subsidiariedad. La construcción de esta ciencia, de modo de hacer efectivamente al menos un poco justiciable aquel principio (por parte de la Corte Constitucional) es hoy una tarea de los estudios penales.

A este fin, deberá darse más espacio a los estudios empíricos, estadísticos, criminológicos, etc., en la construcción de las leyes penales, porque el derecho penal no es simplemente un decálogo, un conjunto de normas de comportamiento, sino también un proyecto político-criminal en la disciplina de un fenómeno social. Sólo así, introduciendo conocimientos empíricos en la construcción de las leyes, también el juez, será autorizado a considerar las reglas como programas de objetivos orientados a las consecuencias, y no sólo como premisas de un silogismo: lo podrá hacer sin ser acusado de utilizar cultura y conocimientos extraños, porque el mismo Parlamento los habrá empleado en fase de construcción de la ley: y esto, tanto más cuanto más debiese afirmarse la idea de que el Parlamento tiene el deber de motivar las leyes penales ${ }^{10}$.

La subsidiariedad, de hecho, no incumbe sólo al legislador cuando construye los ilícitos, esto es, desde el momento en que ella regula la competencia de lo penal respecto de lo extrapenal. La extrema ratio incumbe también a la fase de aplicación de la sanción: el juez debe aplicar la sanción menos grave, cuando la más grave no aparece como necesaria.

Actualmente, la extrema ratio asigna también al juez un papel relevante en el campo de la aplicación de la pena, especialmente con relación a las hipótesis y al fenómeno de la "no punibilidad".

Se trata de una política que, aunque mira a la reducción del derecho penal, toma nota que también en un sistema penal más reducido y menos expandido que el actual, sólo existe la posibilidad de castigar una parte menor de todos los delitos que se cometen y pretende por tanto, racionalizar las opciones que necesariamente van asociadas a este propósito.

No punibilidad significa que hemos dejado atrás la idea grisácea y sacralizada de una justicia sin salida, sin objetivos, que persigue el mismo ideal (y por tanto, gasta los mismos recursos públicos) en cada proceso, en las bagatelas y en los grandes casos, para esclarecer y castigar, tanto el hurto de una bicicleta como una organización criminal internacional. La

\footnotetext{
10 Amplius, sobre tales aspectos, DONINI, Il volto attuale dell'illecito penale. La democrazia penale tra differenziazione e sussidiarietà, Giuffrè, 2004, Cap. IV e IX; ID. La riforma del codice penale tra politica e cultura giuridica, en Questione giust., 2004, spec. 497-509; ID., Sussidiarietà penale e sussidiarietà comunitaria, en Riv. it. di. proc. pen., 2003,141 ss.
} 
justicia se diferencia sabiendo graduar concretamente su respuesta, incluso renunciando a la pena aunque en abstracto se hayan amenazado sanciones graves. No punibilidad significa la existencia de una estrategia diferenciada de causas de reducción o eliminación de la pena, previstas en la ley pero confiadas al juez. El principio que la inspira es, aquí también, el de extrema ratio.

A este fin, la legislación más conforme con la subsidiariedad debería establecer reglas, catálogos de penas alternativas, muy diferenciadas, de las restrictivas o privativas de derechos a las pecuniarias, sustitutivas, etc., que admitan una selección que refleje la extrema ratio, y con ellas un abanico de hipótesis de graduación sancionatoria, hasta la sustitución de una pena criminal con una administrativa y, para terminar, un abanico de hipótesis de no punibilidad en sentido estricto. Las legislaciones contemporáneas han aumentado muchísimo las hipótesis de causas extintivas, de remisiones, de casos de insignificancia, de formas de extinción del delito, de renuncias a la pena seguidas de mediación, reparación del daño, puestas a prueba, etc.

Se obtiene una imagen diversa de la justicia: junto a la idea clásica de un juez que determina una verdad de Estado y distribuye autoritativamente la culpabilidad a sujetos que "experimentan" el juicio y la pena — esta es una idea que queda, se entiende- se afianza aquella de un juez que "dialoga" con el ciudadano, incluso cuando lo castiga, y de aquí una justicia que tiende a la composición de los conflictos, a la misma reconciliación, y no a la mera irrogación de un mal "merecido".

\section{Derecho penal y democracia: antinomias y convergencias de una relación difícil.}

El derecho penal es la rama del ordenamiento jurídico que más tiene que ver con la irracionalidad, que con la violencia y con el mal, irracionalidad de los autores, de las víctimas y del mismo Parlamento que construye las leyes emotivamente, de modo instrumental-simbólico, por razones de mero consenso político o de lucha política, y de este modo sin un examen y un proyecto científico.

El uso político del derecho penal, desvinculado de los controles de racionalidad y de verificación de la extrema ratio, lo ha puesto por ello demasiado libre de perseguir objetivos inconfesables, de volverse un fácil instrumentum regni. La ausencia de motivación de las leyes penales hace que ello sea a menudo directamente injustificable e impresentable.

Frecuentemente, por otro lado, el penalista ve una contradicción entre el derecho penal y la democracia: las "decisiones de la mayoría" no salvaguardan, de seguro, la racionalidad de la construcción de las leyes y la someten a los acuerdos entre partidos. Hay, por tanto, una dialéctica entre derecho penal y democracia que la entendemos sólo como regla mayoritaria. Esta regla, conoce, sin embargo, el límite de los principios y debe, por tanto, ser controlada según la dialéctica entre democracia y constitucionalismo. Los penalistas académicos se ven a sí mismos como intérpretes de un derecho penal elitista de principios, gestionados por una minoría de expertos que pueden dictar leyes superiores a cada parlamento. Las cosas, empero, no están exactamente en estos términos, porque los principios son indisponibles sólo en su núcleo, pero pueden ser realizados políticamente de modo bastante diferente; la misma construcción de los principios es compatible con muchos códigos penales, no impone uno solo. Aquí hay, por tanto, un espacio muy amplio 
de dialéctica "democrática" en la concreción de estos principios. Esta dialéctica viene hoy regulada en medio de concesiones no puramente mayoritarias, pero discursivas y dialógicas de la democracia ${ }^{11}$ : ocurre que las elecciones sobre el castigo son debatidas en el más amplio contexto de la información, porque deben ser motivables o motivadas según los caminos de la razón pública. Ellas no son el coto de caza de unas pocas élites de expertos en principios que carecen de responsabilidad política.

Una relación positiva entre derecho penal y democracia, por tanto, estaría determinada por la posibilidad de un control in fieri, ex ante y expost, sobre las decisiones de la mayoría, en cuanto éstas sean asumidas a la luz de la plena información a la opinión pública: información sobre los datos in input, sobre las razones que están en la base de la ley, sobre los motivos y el análisis jurídico-social en virtud del cual se considera insuficiente la protección extrapenal, sobre la previsión de las consecuencias que la norma se fija; y luego información in output, sobre los resultados de la aplicación de la norma.

Un verdadero control de tales premisas epistemológicas del proyecto legislativo son posibles sólo si se exige la motivación de las leyes penales, como ocurre en Europa, por ejemplo, respecto de las normas de la Unión Europea. Si se requiriese una motivación no sólo sobre los objetivos, sino sobre la base epistemológica que justifica la elección de la sanción penal y sus fines (delito por delito), la comparación entre los límites extremos de una pena respecto a la otra, etc., se obligaría al legislador a una actividad, en definitiva, no necesariamente más racional, pero sí más verificable.

La reserva de ley, en este punto, no sería la garantía formal del respeto de una regla mayoritaria y de la proveniencia de la regla de un órgano político cualificado, sino que sería una reserva en sentido más sustancial: el respeto de un procedimiento que garantice el conocimiento y la información del proyecto legislativo.

Así, en la medida que el sistema pueda evolucionar en esta dirección, que es la única que pueda volver más justiciable la extrema ratio, el intérprete y el poder judicial podrían ya, hoy en día, aumentar las pretensiones de racionalidad de la ley, a través de la verificación de constitucionalidad que es impuesta en los sistemas de control de constitucionalidad concentrado (no "difuso", sino) incidental, esto es, promovido por cualquier juez en el curso de un procedimiento jurisdiccional), pero es necesario también en los sistemas de control preventivo, en cuanto se mantiene el deber de una interpretación conforme con los principios constitucionales y los principios jurídicos internacionales vinculantes.

La aproximación constitucional al derecho penal supone y legitima (pero no necesariamente exige) un juez muy valorativo, que pondera muchísimo, porque debe (en

\footnotetext{
11 Las concesiones dialógicas y procesal-discursivas, a veces en formas deliberativas, de la democracia son numerosas y se insertan en debates muy variados en su interior. Señalo, sólo para una primera profundización, a J. COHEN, Deliberation and Democratic Legitimacy, 17 ss.; ID., Procedure and Substance in Deliberative Democracy, 95 ss.; HABERMAS, Faktizität und Geltung (1992), tr. it., 341 ss., 359 ss.; NINO, The Constitution of Deliberative Democracy, 107 ss.; WALDRON, The Dignity of Legislation (1999), tr. it., 177 ss.; FISHKIN, Democracy and Deliberation, passim; GIDDENS, Beyond Left and Right, passim. Cfr. también RAWLS, The Idea of Public Reason Revisited (1997), 579 s. Un cuadro sintético de las voces a favor y en contra de tales formulaciones en G. SCHMIDT, Demokratietheorien $^{3}, 251$ ss., 261 ss. Para una esquematización de los requisitos institucionales del modelo de democracia consensual como contrapuesto al modelo "Westminster" (o mayoritario) cfr. LIJPHART, Patterns of Democracy (1999), tr. it., 51 ss.
} 
hipótesis) controlar cada ley e interpretarla a la luz de principios superiores. ${ }^{12}$ Este modelo, por tanto, se opone a aquel de un juez-burócrata, que impone al pie de la letra programas condicionales (dado "a" se debe aplicar "b"), pero no significa, por aquello que babiamos dicho anteriormente, la superación de la división de los poderes.

Aquella superación, en primer lugar, no puede acontecer cuando el juez se limita a decidir un caso, sin pretensiones de expresar interpretaciones universales y generalizantes. En efecto, tarea institucional del juez, sea que "interprete" o que "aplique" una norma, no es aportar una hermenéutica generalizante que se adapte a todos los casos, o clasificaciones completas de casos —esto, más bien, es tarea de la doctrina (o la elección personal del magistrado que "hace doctrina") — sino aplicar disposiciones generales a casos particulares, precisando, mediante construcciones normativas más específicas o concretas, grupos o tipologías de "subsupuestos de becho" que, globalmente, enriquezcan la interpretación de la ley, ya sea en términos de generalizaciones conceptuales, o también afincando en estas últimas una dimensión declarada de tópica jurídica ${ }^{13}$. Cuando se limita a realizar aquello, el juez no puede jamás invadir las competencias legislativas, pues por el contrario, es propiamente la ley la que no es competente para decidir los casos.

Es verdad, sin embargo, que en un sistema de civil law, de derecho codificado, la aplicación de la ley comporta siempre una interpretación y cuanto más se tiende a reconducir el caso a la regla, en vez de de la regla al caso, se optará por una lectura generalizadora de la norma. Es aquí que, en los casos difíciles, la discrecionalidad hermenéutica aumenta, integrando las funciones del legislador.

La división de los poderes es superada de hecho, cuando el legislador abdica a opciones claras de política penal con leyes indeterminadas, o cuando su omisión requiere intervenciones de "supletoriedad judicial". La reserva de ley no es violada, sin embargo, por la aplicación de los principios constitucionales en los espacios legítimos de la hermenéutica, sea en los casos difíciles, sea en la reconstrucción del sistema en general (también respecto de los casos aparentemente fáciles).

Cierto: muchos casos son fáciles, pero su disciplina es inconstitucional, en el sentido que la ley es clara y no se puede "suplir" por vía interpretativa, no cabe "reinterpretarla": requeriría sólo su reforma o una declaración de ilegitimidad. Si no existe un control difuso o incidental, sino sólo ex ante, de legitimidad, estos casos no son por regla general de competencia del juez, quien debe aplicar una norma inválida, pero vigente.

Por este motivo, me parece preferible un control de constitucionalidad incidental a uno de carácter anticipado, porque admite que el juzgador, más allá de la interpretación constitucional, pueda dirigirse directamente ante el Tribunal Constitucional cuando la interpretación no basta. No sé en qué medida las potencialidades del recurso de legitimidad incidental estén absorbidas en los poderes del recurso de amparo constitucional, propio de los ordenamientos que conocen este instrumento.

\footnotetext{
${ }^{12}$ Cfr. lo observado en DONINI, Metodo democratico e metodo scientifico, en ID., Alla ricerca di un disegno, 17.

13 Por todos, VIEHWEG, Topik und Jurispruden₹, tr. it., passim; ID., Ideologie und Recbtsdogmatik, 85 ss.; FORNASARI, Ilprincipio di inesigibilità, 181 ss.
} 